\title{
On the role of martensite in the formation of microstructures in heat resistant 9 to $12 \%$ chromium steels
}

\author{
A. Dronhofer, J. Pesicka ${ }^{1}$ and G. Eggeler \\ Institut für Werkstoffe, IA 1/125, Ruhr-Universität Bochum, 44780 Bochum, Germany \\ ${ }^{1}$ Department of Metal Physics, Charles University, Ke Karlovu 5, 12116 Prague, \\ Czech Republic
}

\begin{abstract}
The present work uses transmission electron microscopy to study the formation of the microstructure of a $12 \%$ chromium tempered martensite ferritic steel. The main emphasis placed on the difference between a martensitic material state and the tempered material state. Tempering results in a decrease of dislocation density and in an increase of the width of elongated ferritic micro grains (as opposed to martensitic laths). Adjacent micro grains in the tempered material state are separated by high and low angle boundaries. High angle boundaries are of $\{110\}-$ type.
\end{abstract}

\section{INTRODUCTION}

Tempered martensite ferritic steels (,TMFSs") with chromium contents ranging from 9 to $12 \%$ are used for advanced high temperature components in fossil fired power plants, where they operate in the creep range. TMFSs form martensite on air cooling after the austenitizing heat treatment (e. g. $1 \mathrm{~h} \mathrm{at} 1050^{\circ} \mathrm{C}$ ). After tempering (e. g. $1 \mathrm{~h}$ at $750^{\circ} \mathrm{C}$ ) the microstructure consists of prior austenite grains and a ferritic microstructure with a high density of internal interfaces (high and low angle boundaries) and a high density of dislocations. The microstructure of tempered martensite ferritic steels has been described in the literature and emphasis has been placed on the microstructural hierarchy in these materials [e.g. 1-4]. The formation of the microstructure in these materials is governed by (1) the nucleation and growth of martensite in combination with accommodation processes during cooling from austenitizing temperatures $[5,6]$ and (2) the formation of the ferritic micro grain structure with a high dislocation density and precipitation of carbides during tempering.

TMFSs exhibit a high creep resistance and research in the field of creep has shown that their high creep resistance is due to a combination of substructure and carbide strengthening [e.g. 3,4, 7-10] and the creep hardening mechanism has been addressed as carbide stabilized substructure hardening [4,7]. However, the term substructure hardening only fully applies when the misorientation angle between individual micro grains is small. The important microstructural length scales (micro grain sizes, carbide dimensions) in TMFSs are much smaller than $1 \mu \mathrm{m}$ and can only be detected using transmission electron microscopy (TEM). The present study investigates how the lath martensite microstructure (before tempering) transforms into elongated ferritic micro grains (after tempering). Preliminary results on misorientations between adjacent micro grains are presented. Emphasis is also placed on the widths of martensite laths (in the martensite) and of the elongated micro grains (after tempering). Moreover preliminary results on dislocation densities in the material before and after tempering are reported.

\section{EXPERIMENTS}

A chromium steel with $12 \%$ chromium and $0,2 \%$ carbon (German grade X20 CrMoV 12 1) was investigated in the present study. This material is one of the first generation TMFSs which was widely used in energy technology. It was chosen for the present study because of its high carbon content (if carbides play a role in the formation of TMFS micro grain morphology this can be most easily shown in a material with a high carbide volume fraction). The as received material investigated in the present study was subjected to two heat treatments. One microstructural state was obtained by austenitizing for 1 hour at $1050^{\circ} \mathrm{C}$ and air cooling (Figures $\mathrm{Ia}$ and $2 \mathrm{a}$ ). This heat treatment resulted in a martensitic microstructure 
with a Vickers hardness of 618 HV30. A second material state was obtained by applying the same austenitization treatment followed by an additional tempering treatment, 1 hour at $750^{\circ} \mathrm{C}$ (Figures $1 \mathrm{~b}$ and $2 \mathrm{~b}$ ). The hardness after this heat treatment was 285 HV30. Figure 1 shows micrographs of the martensitic and tempered material state which were obtained using scanning electron microscopy (SEM). Prior to SEM investigation specimens were polished and etched. The TEM microstructures of the two material states are presented in Figure 2. Transmission electron microscopy (TEM) was performed using a Philips CM20 analytical microscope operating at 200kV. TEM foils were thinned by a standard double jet technique. Experimental details will be reported elsewhere [11].

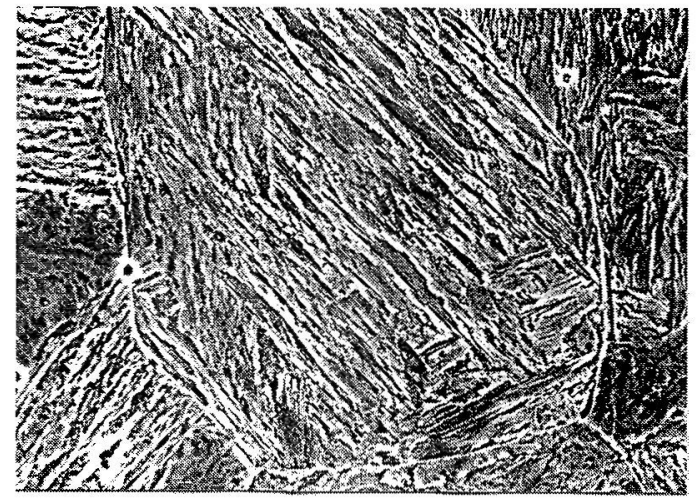

(a)

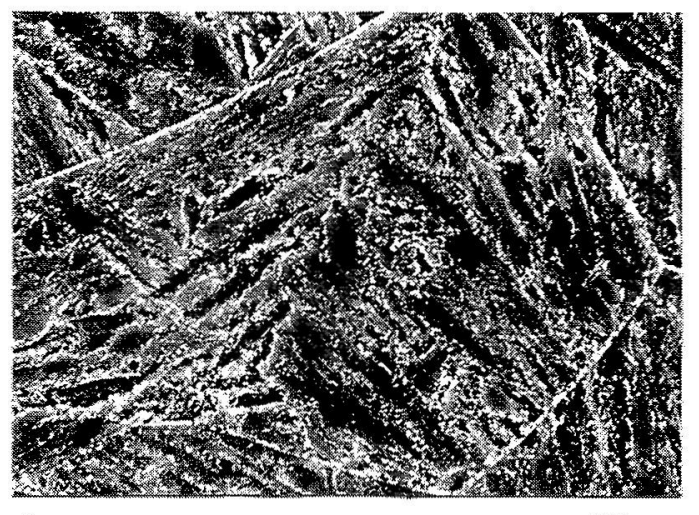

(b)

$10 \mu \mathrm{m}$

Figure 1: SEM micrographs of the two material states investigated in the present study. (a) Martensitic material state. (b) Microstructure after tempering.

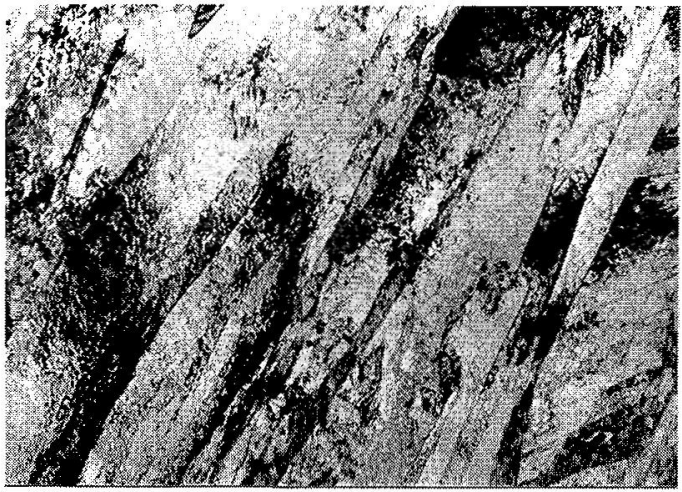

(a)

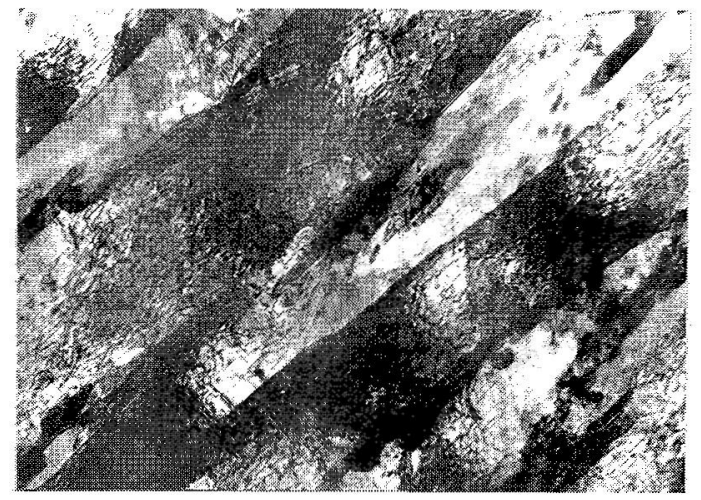

(b)

$500 \mathrm{~nm}$

Figure 2: TEM micrographs of the two material states investigated in the present study. (a) Martensitic material state. (b) Microstructure after tempering.

As can be seen from Figure 1 there is no big difference in the SEM micrographs between the martensitic and tempered microstructure. The white spots on the prior austenite grain boundaries of Figure $1 \mathrm{~b}$ represent grain boundary carbides which can also be seen in the TEM micrograph of Figure $2 b$. No carbides can be found in the martensitic material state while there are carbides both on prior austenite and micro grain boundaries after tempering. From TEM micrographs like those shown in Figure 2, the widths of martensite laths and of micro grains after tempering were measured. A total of 16 TEM micrographs ( 8 for the martensitic and 8 for the tempered material state) were evaluated. The widths of 121 martensite laths and 109 micro grains after tempering were assessed using the image analysis software DIAna [12]; 
in the present study the mean widths results are reported. The corresponding size distributions will be published elsewhere [11]. Moreover, an attempt was made to quantify the dislocation densities in the martensitic and tempered material state using a line intersection method. 3 TEM micrographs with 4 test lines each were evaluated for the martensitic material state; 6 TEM micrographs with 4 test lines each were evaluated for the tempered material state. Details on the dislocation density measurements will be published elsewhere [11].

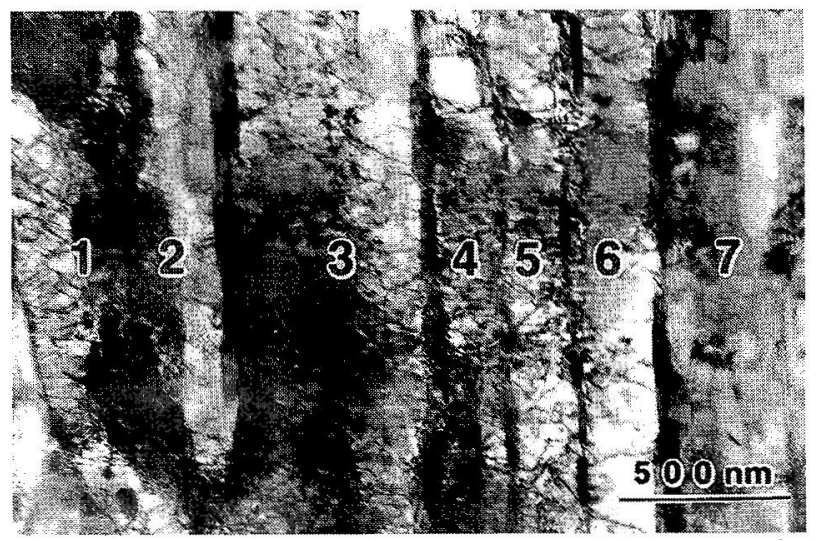

Figure 3: TEM micrograph of the tempered material showing 7 adjacent grains (numbered 1 to 7 ). The picture was taken using the two beam condition from one micro grain (see Figure 4a).

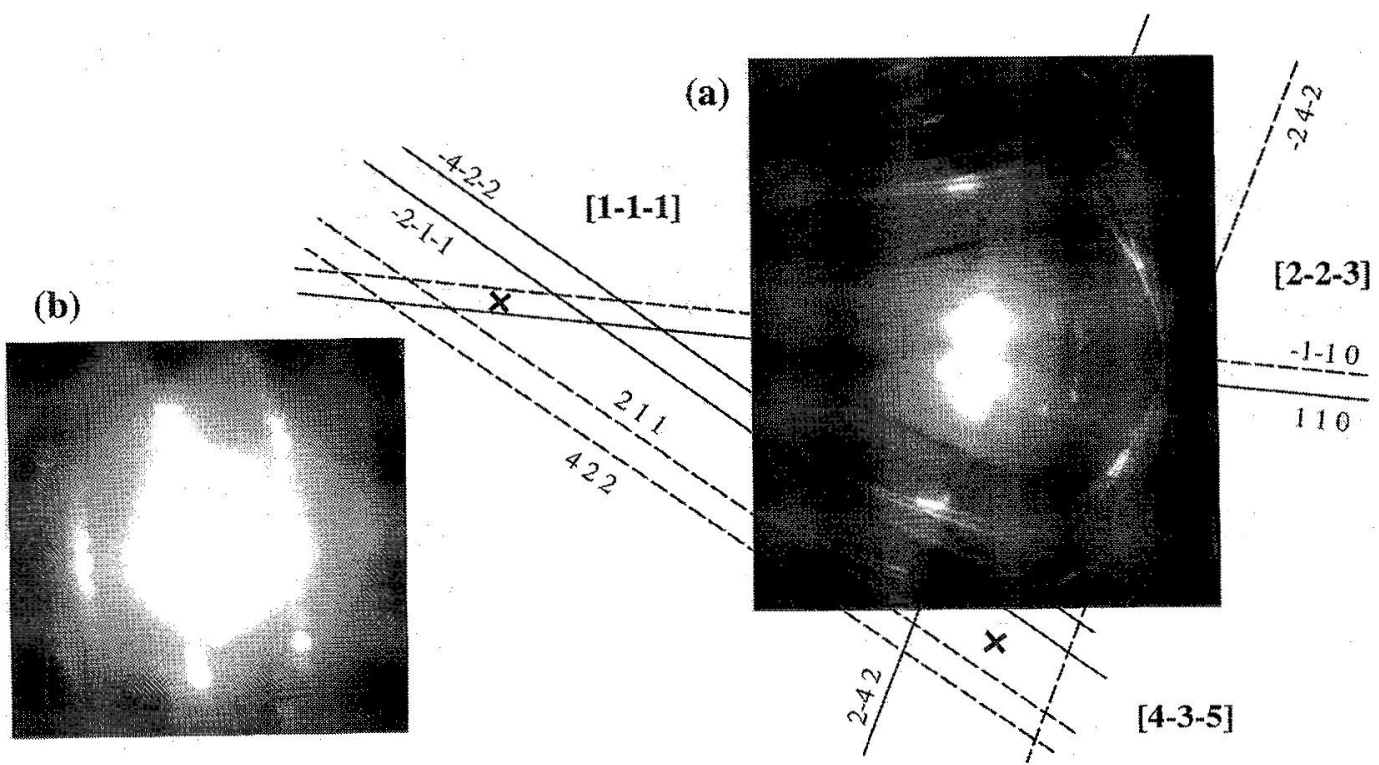

Figure 4: CBED patterns from the (a) tempered (micro grain 6 from Figure 3) and (b) martensitic material state. No Kikuchi lines could be obtained for the martensitic material state.

The crystallographic orientations of the seven adjacent micro grains in the tempered material state shown in the TEM micrograph of Figure 3 were determined using Kikuchi line diffraction patterns obtained by convergent beam electron diffraction (CBED). The Kikuchi line pattern for micro grain 6 (from Figure 3) is shown in Figure 4a. Figure $4 \mathrm{~b}$ shows a CBED pattern of the martensite where no Kikuchi lines can be 
obtained. The misorientation between two individual micro grains in Figure 3 was characterized by determining the rotation axis and the rotation angle which are required to project one crystal lattice onto the other. A MATHEMATICA routine was used to obtain the spatial directions of the corresponding rotation axis and the rotation angles from the Kikuchi line CBED patterns of the two misoriented crystals [13].

\section{RESULTS AND DISCUSSION}

Width measurements and dislocation densities show a considerable scatter in both material states. Nevertheless, the mean width of the elongated micro grains of the tempered material was higher than the mean widths of the laths in the martensite, Table 1. Very high dislocation densities were observed in the martensitic and in the tempered material state, Table 1 . Nevertheless, the average dislocation density in the martensite is significantly higher than the dislocation density after tempering.

Table 1: Overview summary of average widths (of laths in martensitic and elongated micro grains in tempered material state) and of dislocation densities.

\begin{tabular}{|c|c|c|}
\hline X20 CrMoV 121 & $\begin{array}{c}\text { mean width [nm] } \\
\text { lath / micro grain }\end{array}$ & $\begin{array}{c}\text { average dislocation } \\
\text { density }\left[\mathbf{m}^{-2}\right]\end{array}$ \\
\hline martensitic state & 585 & $1 \times 10^{15}$ \\
\hline tempered state & 726 & $3 \times 10^{14}$ \\
\hline
\end{tabular}

The results of the misorientation measurements are presented in Table 2. The left column of Table 2 indicates for which two micro grains from Figure 3 the misorientation was measured. The second and third column of Table 2 show the crystallographic orientation of the rotation axis and the rotation angle required to perform the symmetry operation. In addition to the orientations between all adjacent micro grains, the orientations between grains 1 and 3 and between grains 2 and 7 were determined.

Table 2: Results of the misorientation measurements performed for the micro grains of Figure 3. Column 1: Two micro grains from Figure 3 for which misorientation was measured. Column 2: Orientation of rotation axis. Column 3: Rotation angle.

\begin{tabular}{|c|c|c|}
\hline $\begin{array}{c}\text { rotation between } \\
\text { micro grains }\end{array}$ & rotation axis $\left[\mathbf{h}_{\Theta} \mathbf{k}_{\Theta} \mathbf{l}_{\Theta}\right]$ & rotation angle $\left[\Theta\right.$ in $\left.^{\circ}\right]$ \\
\hline $1 / 2$ & {$\left[\begin{array}{lll}-146 & -137 & 6\end{array}\right]$} & 71 \\
\hline $2 / 3$ & {$\left[\begin{array}{lll}-163-114 & 20\end{array}\right]$} & 16 \\
\hline $3 / 4$ & {$\left[\begin{array}{lll}178 & 91 & -6\end{array}\right]$} & 2 \\
\hline $4 / 5$ & {$\left[\begin{array}{lll}-105 & 169 & 18\end{array}\right]$} & 5 \\
\hline $5 / 6$ & {$\left[\begin{array}{lll}179 & 20 & -86\end{array}\right]$} & 4 \\
\hline $6 / 7$ & {$\left[\begin{array}{lll}-144 & -139 & 11\end{array}\right]$} & 16 \\
\hline $1 / 3$ & {$\left[\begin{array}{lll}-138 & -145 & 8\end{array}\right]$} & 55 \\
\hline $2 / 7$ & {$\left[\begin{array}{lll}-152 & 121 & -46\end{array}\right]$} & 2 \\
\hline
\end{tabular}

In addition to the rotation axis and angles between the adjacent grains, Table 3 contains the rotational relations between grain 1 and 3 and between grain 2 and 7 . It can be seen that the angle between grain 1 and 3 results from the difference between the two rotation angles between the first two pairs of adjacent grains. It is interesting to note that the rotation angle between grain 2 and grain 7 is very small. Figure 5 shows a schematic representation of the results from Figure 3 and Table 3. Its upper part schematically represents the microstructure shown in Figure 3. Figure 5 shows all rotation angles which are listed in Table 3. Solid and dashed line segments connect positions A and B in the upper part of Figure 5 where a 
view direction (A-B) is defined. The solid parts of the lines represent the part of the crystals which are schematically illustrated in the lower part of Figure 5 (view A-B) which schematically illustrates the degree of rotation within the micro grains.

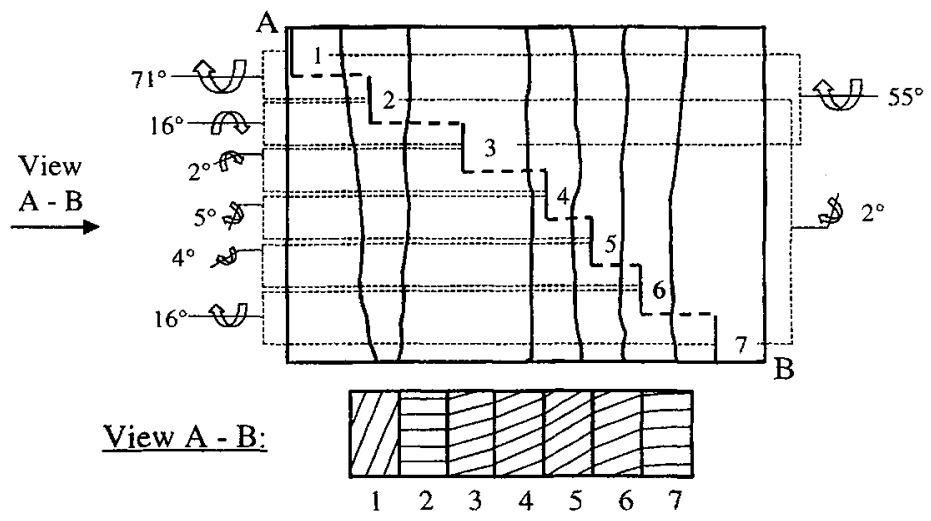

Figure 5: Schematic illustration of the rotation angles between individual micro grains from Figure 3. Upper part of the figure: Schematic representation of the microstructure and definition of view A-B. Lower part of the figure: Schematic illustration of the rotation between individual micro grains of Figure 3. See text for explanation of figure.

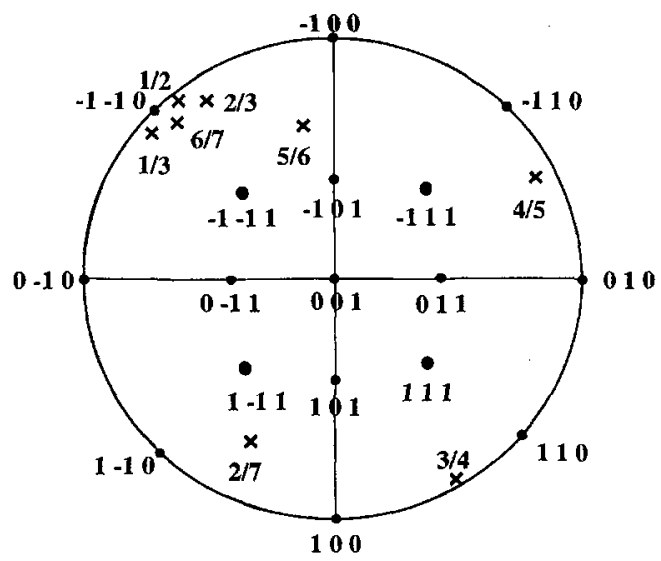

Figure 6: $(00 \mathrm{I})$-projection showing the orientation of rotation axis for symmetry operations between micro grains in Figure 3. Rotation axis which are associated with high misorientations are seen to be close to $(-1-10)$

It is now interesting to present the directions of the rotation axis in the (001)-projection of the cubic lattice in Figure 6. The rotation axis of all symmetry operations required for two micro grains with a high degree of misorientation (rotation angles $>10^{\circ}$ ) yield poles which are close to (-1-10), Figure 6 . The orientation axis of micro grain pairs with small misorientations (rotation angles $<10^{\circ}$ ) have arbitrary crystallographic orientations. Within the microstructural region shown in Figure 3 high rotation angles are associated with interfaces of type $\{110\}$ which represent glide planes in the cubic body centered lattice.

\section{SUMMARY AND CONCLUSIONS}

In the present study the formation of microstructures of a $12 \%$ chromium tempered martensite ferritic steel (TMFS) was investigated. Using transmission electron microscopy (TEM). The following results were obtained: (1) Air cooling from the austenitic region produces a fully martensitic microstructure. The 
dislocation density in the martensite lath is high and there is evidence for mechanical twinning (not shown; to be published in [11]). The dislocations and deformation twins indicate that there are lattice invariant accommodation processes which minimize the elastic strain energy associated with the formation of martensite. (2) During tempering the martensitic structure transforms into a ferritic structure with small micro grains. The width of the elongated micro grains is wider than the width of the martensite laths (prior to tempering). The dislocation density decreases from the martensitic state but remains high $\left(3 \times 10^{14} \mathrm{~m}^{-2}\right)$. (3) An attempt was made to study misorientations between adjacent micro grains in the tempered material state. Low angle and high angle boundaries were identified using convergent beam electron diffraction (CBED). High angle misorientations (angle $>10^{\circ}$ ) were shown to be associated with $\{110\}$-boundaries. Two micro grains (2 and 7 in Figure 3 ) with almost the same crystallography orientation were found to be highly misoriented with respect to the other micro grains. We interpret this as another type of accommodation process by the formation of the suitable combination of martensite variants (here: variant 1 - grains 3,4,5,6; variant 2 - grains 2 and 7), which result in the formation of misoriented micro grains after tempering. The microstructural region in Figure 3 represents what Matsuda et al. have termed a co-variant packet [14]. No hard correlation between the number fraction of carbides and the crystallographic nature of the boundaries could be identified and further work is required to clarify this point.

\section{Acknowledgements}

$\mathrm{AD}$ and GE wish to thank the Deutsche Forschungsgemeinschaft for funding under contract EG 101/1. JP acknowledges funding in the framework of the Grant Agency of Charles University, Project 162/2000.

\section{References}

1. G.B. Olson, in Proc. of the Intern. Conf. on Displacive Phase Transformations and Their Applications in Materials Engineering, edited by K. Inoue et al., TMS, Warrendale 1998, 15.

2. A. Göcmen, Grundrisse der Gefügeausbildung und der Zeitstandeigenschaften Martensitischer 912\% Chromstähle, Ph-D Thesis (in German), Swiss Federal Institute of Technology, Zürich 1997 (Diss. ETH Nr. 12020).

3. G. Eggeler, N. Nilsvang, B. Ilschner, Steel Research, 58 (1987) 97.

4. G. Eggeler, Acta Metall., 37 (1989) 3225.

5. L. Delaey: Diffusionless Transformations, in Phase Transformations in Materials, edited by P. Haasen, Materials Science and Technology - Volume 5, VCH, Weinheim 1991.

6. H.K.D.H. Bhadeshia, Bainite in Steels, The Institute of Materials, London 1992.

7. G. Eggeler, N. Nilsvang and B. Ilschner, in Strength of Metals and Alloys, ICSMA 9, edited by: D.G. Brandon et al., Volume 1, Freund Publishing Company Ltd., London 1991, 351.

8. K. Kucharova, J. Nemec and A. Dlouhy, in Proc. of the 7th Intern. Conf. on Creep and Fracture of Engineering Materials and Structures, edited by: J.C. Earthman and F. A. Mohamed, TMS, Warrendale, 1997, 79.

9. G. Eggeler, J. Hald, M. Cans, J. Phillips, in Proc. of the 5th Intern. Conf. on Creep and Fracture of Engineering Materials and Structures, edited by: B. Wilshire and R. W. Evand, The Institute of Materials, London 1993, 527.

10. P. Polcik, Modellierung des Verformungsverhaltens der warmfesten $9 / 12 \%$ Chromstähle im Temperaturbereich von 550-650 $0^{\circ}$, Ph-D Thesis (in German), Shaker Verlag, Aachen 1999 (D29 Dissertation Universität Erlangen Nürnberg).

11. A. Dronhofer, J. Pešička, G. Eggeler, to be published

12. DIAna 1.2, J. Duyster, Ruhr-Universität Bochum (1991-97)

13. A. Dlouhy, to be published

14. S. Matsuda, T. Inoue, M. Ogasaswara, Trans. Japan Inst. Met. 9, 1968, 343 